\title{
New Challenges of Livestock to Climate Change and Overpopulation
}

\author{
Cristina Castillo* \\ Department of Animal Pathology, Universidade de Santiago de Compostela, Spain
}

*Corresponding author: Cristina Castillo, Department of Animal Pathology, College of Veterinary Medicine, Universidade de Santiago de Compostela, Spain

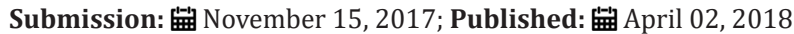

\section{Introduction}

In recent years there has been a great euphoria about the application of biotechnology to the livestock rearing and the potential benefits in search of effective and sustainable farming systems that can meet the challenge of global overpopulation in 2050 according to the Food and Agriculture Organization (FAO) report published in 2009 (How to Feed the World in 2050). In parallel to these demands, are several researchers who claim to the United Nations a plan of action that serves to strengthen the rural sector, a clear decline worldwide, constituting a global concern [1]. Therefore, the food needs that are foreseen in a near future can only be covered if the agricultural sector is helped by political measures that favor livestock production and farmer's life quality.

Agriculture (livestock and crops) would need to keep pace with the projected demands from population growth and where dietary changes (especially meat consumption) are suggested [2]. However, the new shifts proposed in relation to dietary changes from grain-fed beef consumption in poultry or pork is not a realistic goal. Currently, animal production already represents more than a third of the gross domestic product (GDP) in developed countries and is expected to continue to increase.

In the last decade, research and the application of new technologies related to animal reproduction has evolved in an accelerated way, resulting in the development of techniques that increase the reproductive capacity of bovine livestock, allowing greater progress in genetic improvements. The techniques that have received most attention are artificial insemination, super ovulation, in vitro fertilization, embryo culture, transfer and freezing, sexing of semen and embryos and, more recently, embryo cloning [3].

Biotechnology has also contributed to modify cattle nutrition. As several authors (4) point out point out around $70 \%$ of the grains used by developed countries is fed to animals. Of the world's third of grains destined to the feeding of livestock, $40 \%$ is destined to feed cattle. Although crop production increased by $47 \%$ between 1985 and 2005, in the face of the world's population growth there will be a stiff competition between food destined to the human being and destined to livestock. In fact, current intensification of beef and dairy production, under economic pressure, dictates that cattle must gain weight at their maximum potential rate involving them quickly onto a full feed of a diet containing a high concentration of grain. In fact, current intensification of beef and dairy production, under economic pressure, dictates that cattle must gain weight at their maximum potential rate involving them quickly onto a full feed of a diet containing a high concentration of grain. These conditions stimulated in the last decades a wide variety of technology that favored a greater digestibility of grain's starch (5).

The new challenge is how livestock farmers can cope with the new era (overpopulation) and environmental sustainability. There are a number of obstacles such as land degradation, environmental pollution, global warming, erosion of animal genetic resources, water scarcity and new diseases, which threaten the growth of the global livestock sector. However, these challenges cannot be equally considered worldwide. The new biotechnology approaches would be different depending on whether the farming system is located in a developing country or not, whether it is under intensive or organic systems, and so on [6].

From reading different literature sources, it is clear that the advances in the agricultural sector (crops and livestock) worldwide in a sustainable scenario will require the use of new technological tools (biological or not) with the engagement of a wide variety of disciplines ranging from veterinarians, agronomists, economists, biologists, geneticists, microbiologists, food-policy makers, engineers, bioinformaticians and farmers. In addition, the technological developments should not be only focused towards new management practices, nutrition or genetic improvement of cattle, but also the increase in quality and safety of the final product: meat and/or milk. Livestock production should direct their research advances towards this line, offering to consumer's products with the highest standards of quality, flavor and safety.

Livestock production should direct their research advances towards this line, offering to consumer's products with the highest 
standards of quality, flavor and safety. Biosafety is, therefore an issue of great concern worldwide.. Environmental and ethical concerns have promoted in the last years the development of in vitro meat [6] that would unquestionably be hugely disruptive to the traditional livestock sector and that not represent a worldwide solution. The challenge in this sense is work on live animals, improving the technological procedures. According with the abovementioned information, in a near-future, scientists will be involved in new biotechnology approaches beyond that which is already well-known such as

Employment of genetically modified crops (GMC) able to withstand environmental stressors allowing the growth of sustainable farming and the economical developing in low-income countries that depend on agricultural sector (7).

The search of new feedstuffs for livestock including crop residues or new forage sources, and/or using fruit and vegetable wastes (FVW) and by-products from the fruit and vegetable processing industry that are available worldwide for cattle nutrition [8].

Genetic improvement That could help to breed cattle that are more disease-resistant, reducing antibiotic use and the likelihood of the emergence of antibiotic-resistant bacteria. Included in this paragraph genetics would also contribute to manipulation of rumen microbiota, improving livestock production in terms of feed efficiency and milk, and minimizing $\mathrm{CH}_{4}$ emissions [9]. In relation with the growing interest in the post-rumen microbiota and its role in the control of $\mathrm{CH}_{4}$ production, In relation with the growing interest in the post-rumen microbiota and its role in the control of $\mathrm{CH}_{4}$ production, a recent study (10) established through real-time PCR analysis that in dairy cattle, the natural fecal archaeal community is predominated by Methanobrevibacter $(86.9 \%$ of the total) and Methanocorpusculum (10.4\%), with other populations being less predominant (below 1\%) such as Methanosphaera (0.8\%), and Thermoplasma (0.4\%), with Candidatus Nitrososphaera and Halalkalicoccus being close to zero. As next-generation sequencing platforms and chemistries continue to expand and improve, we expect that major advancements in sequencing may contribute to significant improvements in dairy production by improving nutrition and management that support a production efficient microbiota that minimizes $\mathrm{CH}_{4}$ emissions.

Application of nanotechnology looking for the improvement of livestock's fertility; in fact,low fertility results in low production rate, increases in financial input, and reduced efficiency of livestock operations. This emerging field offers remarkable opportunities for challenging researchers to provide new solutions to old issues, and has the potential to demonstrate continuous forward progress in the next years.

Re-defining the production systems Towards the design of low-energy sustainable buildings. Thus, the hybrid system in livestock productions could include buildings that meet standards for environmentally friendly design, construction and operation within the new trend called green construction or sustainable buildings that offers great opportunities for research and innovation [6]. From a more conventional perspective, there are very significant opportunities to reduce contaminant emissions (mainly $\mathrm{CH}_{4}$ ) from animal-sourced food production systems. Thus livestock accounts for up to half of the technical mitigation potential of the agriculture, forestry and land-use sectors, through management options that sustainably intensify livestock production, promote carbon sequestration in rangelands and reduce emissions from manures, and through reductions in the demand for livestock products [11] livestock accounts for up to half of the technical mitigation potential of the agriculture, forestry and land-use sectors, through management options that sustainably intensify livestock production, promote carbon sequestration in rangelands and reduce emissions from manures, and through reductions in the demand for livestock products.

Development of synthetic biology and synthetic chemistry technologies To meet the demand for novel vaccines to respond rapidly to viral pandemics and address the economic burden of untreated diseases. The use and misuse of antibiotics in farm animal settings as growth promoters or as nonspecific means of infection prevention and treatment has boosted antibiotic consumption and resistance among bacteria in animal's habitats. This reservoir of resistance can be transmitted to humans through food consumption. Nanotechnology-based drugs and vaccines can be effective alternatives for the treatment/prevention of infectious diseases, decreasing the environmental risks associated with the use of antibiotics [12]

Increase the research efforts towards the concept food fortification The technological developments should be also focused to increase the quality and safety of the final product: meat and/or milk, offering to consumer's products with the highest standards of quality, flavor and safety [13]. Biosafety is, therefore an issue of great concern worldwide. In this sense, the review performed by [14] showed that supplementation with dietary antioxidants is able to improve both milk and meat characteristics under intensive conditions, maintaining their quality during processing, packaging and distribution, offering to consumer's products with the highest standards of quality, flavor and safety. Biosafety is, therefore an issue of great concern worldwide. Nevertheless, there is a wide spectrum for research in this area.

The potential antioxidant role of natural plant extracts is an interesting field to explore, in line with the consumer's criteria related to any additive: safety. Their positive effects are attributable to three mechanisms: free-radical scavenging activity, transitionmetal-chelating activity, and/or singlet oxygen-quenching capacity [15]. The use of synthetic antioxidants, such as butylated hydroxyanisole (BHA), butylated hydroxytoluene (BHT), and tertiary butyl hydroquinone (TBHQ), have been employed in inhibiting meat oxidation but they cause toxicological effects [16] giving more relevance to the use of natural antioxidants.

Increase the control of residues in milk and beef 
products Chemical contaminations of beef and milk can be due to chemicals, like agrochemicals (primarily residues of veterinary medicines and pesticides), environmental contaminants (primarily heavy metals, persistent organic pollutants and natural toxins) and processing contaminants [17]. Certainly, as food importation from different parts of the world increases, biotechnology is necessary, as is working in a food-safety environment. It is necessary to examine sanitary conditions and manufacturing processes, ensure proper food labeling and collect samples for laboratory testing. In this sense, emerging laboratory technologies in association with bioinformaticians try to develop a predictive system that seeks to find the root causes of food contamination. The purpose is to establish baselines for microbial communities that would act as a global benchmark [18].

\section{Improve the waste disposal on farms}

Globally, $55 \%$ of the total $\mathrm{CH}_{4}$ produced comes from the agricultural sector. Livestock is an important emitter of greenhouse emissions (GHG), but it also has the potential to significantly reduce its emissions. It is necessary a global research assessing the magnitude, the sources and pathways of emissions from different livestock production systems and supply chains. On this basis would be possible to offer concrete options to reduce emissions [19].

Promote the development of social networks and informatics to the service of farmer One of the major global challenges in the near future is getting the relevant agricultural and farming innovations into the hands of the world's poor farmers, such as those in south Asia and Sub-Saharan Africa. Currently, Food and Agricultural research continues to be concentrated in just a handful of nations. Curiously, those regions of the world that are experiencing the highest rates of population growth, are the places where per capita investment in Food and Agricultural research is among the lowest in the world. Thus, apps, software and websites that recognize farmers as innovators, not just managers, are increasing. There are open-source communities in which mainly small-scale farmers share their knowledge, doubts, tools and designs. Farmers, not only scientists or outreach workers, are the essential players in any agricultural innovation system. This technological innovation is particularly relevant in those places or countries where farms are distanced from each other, losing information or where livestock resources are scarce [6].

This trend is part of the larger movement toward precision agriculture (including farming), where technology is woven into every aspect of a farmer's life: GPS-guided tractors that drive themselves, robotic milking machines, and other such things have passed from the realm of agricultural sci-fi to practically status quo in the world of industrial agriculture [20].These examples illustrate the easy with which researchers are migrating their science from the lab to the field, collecting in situ medically relevant data. Recently mobile phones (like smart phones) are helping to take conventional laboratory-based science into the field; more useful in "resource-poor" environments or remote locales [21].

\section{Conclusion}

As can be seen, livestock sector is obliged to adapt to the new challenges, although depending on the part of the world. Finally, we would like to emphasize that climate change is not a matter for developing or developed countries alone; it affects the whole planet. While in developed areas it will be necessary to change certain approaches, especially in the European Union (EU) or United States (US) (facilities, management, crops, etc.), in lowincome countries, biotechnology must provide the farmers with the tools and knowledge acquired to promote farming (cattle and agriculture) and let them out of its state of eternal poverty.

\section{References}

1. Liu Y, Li Y (2017) Revitalize the world's countryside. Nature 548(7667):275-277.

2. Foley JA (2011) Rammankutty N, Brauman KA, Cassidy ES, Gerber JS, et al. (2011) Solutions for a cultivated planet. Nature 478: 337-342.

3. Felmer R, Arias ME, Muñoz G (2007) Transferencia nuclear de células somáticas (clonación): aplicaciones en producción animal y biotecnología. Revista Tierra Adentro 77: 42-45.

4. Eisler MC, Tarlton JF, Martin GB, Beddington J, Dungait JAJ, et al. (2014) Steps to sustainable livestock. Nature 507(7490): 32-34.

5. Castillo C, Benedito JL, Méndez J, Pereira V, López Alonso M, et al. (2004) Organic acids as a substitute for monensin in diets for beef cattle. Animal Feed Science and Technology 115: 101-116.

6. Castillo C, Abuelo A, Hernández J (2017) Biotechnological Approaches to Improve Sustainable Milk and Meat Yield in Bovines. Reference Module in Food Sciences. Elsevier 1-27.

7. Azadi H, Samiee A, Mahmoudi H, Jouzi, Z, Khachak PR, et al. (2016) Genetically modified crops and small-scale farmers: main opportunities and challenges. Crit Rev Biotechnol 36(3): 434-446.

8. Wadhwa M, Bakshi MPS (2013) Utilization of fruit and vegetable wastes as livestock feed and as substrates for generation of other value-added products. RAP Publication.

9. Weimer PJ (2015) Redundancy, resilience, and host specificity of the ruminal microbiota: implications for engineering improved ruminal fermentations. Front Microbial 6: 296.

10. Jin D, Kang K, Wang H, Wang Z, Xue B, et al. (2017) Effects of dietary supplementation of active dried yeast on fecal methanogenic archaea diversity in dairy cows. Anaerobe 44: 78-86.

11. Rijsberman F (2017) The key role of the meat industry in transformation to a low-carbon, climate resilient, sustainable economy. Meat Sci 132: $2-5$.

12. Mir SA, Shah MA, Mir MM, IqbalU (2017) New horizons in nanotechnology in agriculture and food processing industry. In: Nayak BK, Nanda A, Bhat MA (Eds), Integrating biologically-inspired nanotechnology into medical practice., IGI Global, Hershey (PA), USA, pp: 230-258.

13. Swieca M, Sczyk Ł, Gawlik Dziki U, Dziki D (2014) Bread enriched with quinoa leaves-the influence of protein-phenolics interactions on the nutritional and antioxidant quality. Food Chem 162: 54-62.

14. Castillo, C., Pereira, V., Abuelo, A., Hernández, J., 2013. Effect of supplementation with antioxidants on the quality of bovine milk and meat production. Sci. World J. Article ID 616098.

15. Sharma AK, Gangwar M, Tilak R, Nath G, Sinha ASK, et al. (2012) Comparative in vitro antimicrobial and phytochemical evaluation of methanolic extract of root, stem and leaf of Jatropha curcas Linn. Pharmacognosy Journal 4(30): 34-40. 
16. Falowo AB, P Fayemi PO, Muchenje V (2015) Natural antioxidants against lipid-protein oxidative deterioration in meat and meat products: A review. Food Research International 64(30): 171-181.

17. Cooper KM, McMahon C, Fair weather I, Elliott CT (2015) Potential impacts of climate change on veterinary medicinal residues in livestock produce: An island of Ireland perspective. Trends in Food Science and Technology 44(1): 21-35.
18. Crean D (2015) Feeding the 10 billion. Sponsor feature. Nature 526.

19. Gerber PJ, Steinfeld H, Henderson B, Mottet A, Opio C, et al. (2013) Tackling climate change through livestock. A global assessment of emissions and mitigation opportunities. CAB International, UK.

20. Barth B (2016) Luddites, Beware: These 5 Livestock Wearable Are the Future.

21. Perkel JM (2017) Pocket laboratories. Nature 545: 119-121.
Creative Commons Attribution 4.0 International License

For possible submissions Click Here

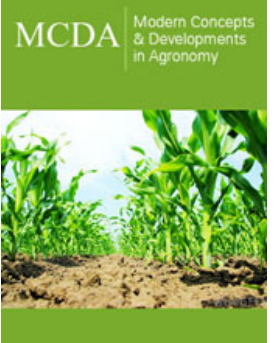

Modern Concepts \& Developments in Agronomy

\section{Benefits of Publishing with us}

- High-level peer review and editorial services

- Freely accessible online immediately upon publication

- Authors retain the copyright to their work

- Licensing it under a Creative Commons license

- Visibility through different online platforms 